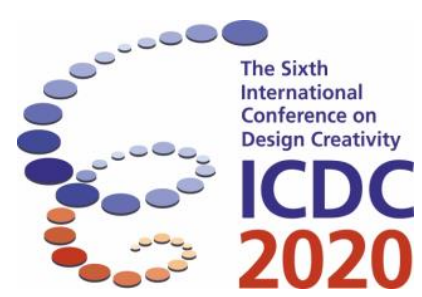

\title{
Value conflict, convergence and evolution - values shaping cross-disciplinary design
}

\author{
Netta Iivari
}

INTERACT Research Unit, University of Oulu, Oulu, Finland

\begin{abstract}
Values are shaping and underlying our behaviour, including creative design. In crossdisciplinary design, there may be a multitude of values shaping and underlying design. So far, there is a lack of studies on values in cross-disciplinary design. This study utilizes a value lens to examine cross-disciplinary design of a learning application within which Human Computer Interaction (HCI), educational science and Information Technology (IT) specialists as well as users acted as design participants. The study reveals numerous values implicated in design. Educational science specialists emphasized a multitude of values; sometimes even conflicting ones, in their design for learners, while HCI specialists and IT specialists advocated Security and Self-Actualization values for users. Both value conflicts and convergence emerged and those were identified both between and among these designer groups as well as between designers and users. Evolution and negotiation of values was also observable. Implications for research and practice are discussed.
\end{abstract}

Keywords: values, cross-disciplinary design, multiparty design, creative design

\section{Introduction}

Digital technology has become thoroughly embedded in our everyday life, including work and leisure. It has a potential of enriching and elevating our life but also of making it miserable. Despite of plenty of participatory and user- and human oriented methods, there still are many open issues and challenges involved in creating high quality solutions for human use. One complicating factor is that nowadays design involves collaboration among different stakeholders representing e.g. multiple organizations, professions, areas of expertise, and disciplines, (e.g. Lee 2007, Levina 2006, Newell \& Galliers 2000). In such a design setting, communicating, collaborating, and arriving at shared understandings may be very challenging (Lee 2007, Levina 2006, Newell \& Galliers 2000).

Moreover, albeit the extant research already provides interesting insights on the tensions and complexities involved in multiparty or cross-disciplinary design, it lacks an explicit perspective on the influence of values intermingled with such a process. Values, in general, are significant as driving and underlying human behaviour. Their significance has been acknowledged also in research addressing design (e.g. Friedman et al. 2013, Halloran et al. 2009, Hartikainen et al. 2019, Iivari et al. 2015, Iversen et al. 2010, Iversen et al. 2012, Le Dantec et al. 2009, Miller et al. 2007, Nouwen et al. 2015) and use (e.g. Isomursu et al. 2011, Kinnula et al. 2018, Nouwen et al. 2015, Zaman \& Abeele 2010). However, there is a lack of empirical research examining how values are intermingled with and shaping cross-disciplinary design. The research question examined in this paper asks, what kind of values and related dynamics shape cross-disciplinary design. The question is answered through an 
interpretive case study on a cross-disciplinary design project of a learning application. The project aimed entailed a multinational and cross-disciplinary design team collaborating in creative design.

\section{Related research}

Nowadays design often is a multiparty and cross-disciplinary endeavour (e.g. Gasson 2012, Hekkala \& Urquhardt 2013, Lee 2007, Levina 2006, Rosenkranz et al. 2014). There may be, for example, marketing, strategy, graphic design, educators, artists, developers and users from different organizations involved (Lee 2007, Levina 2006). In this type of multiparty or cross-disciplinary design, collaboration can be very challenging (Lee 2007). Work practices of different disciplines may vary greatly as well as their ontological, epistemological, and methodological assumptions (Cummings \& Kiesler 2003, Newell \& Galliers 2000). There is an extended need for discussion, negotiation, and learning, as there may be discrepancies in team members' goals, language, assumptions, practices, and understandings (Bergman et al. 2007, Levina 2006, Schutz et al. 2009). Despite this body of research on the topic, there is blind spot in understanding the values driving cross-disciplinary design.

The importance of values in driving and underlying human behaviour has been acknowledged within a number of disciplines, for example psychology, marketing and management (e.g. Denison and Spreitzer 1991, Schwartz 1992, Schwartz 1994). Values tell us what is considered important, good and right in life (Friedman et al. 2013, Iversen et al. 2010, Miller et al. 2007). Different kinds of value categorizations and instruments for examining values have been developed (e.g. Denison and Spreitzer 1991, Schwartz 1992, Schwartz 1994). In research on technology design and use, some studies have already utilized those (e.g. Hartikainen et al. 2019, Isomursu et al. 2011, Kinnula et al. 2018); alternatively, some have approached values as an open question - seeing values are to be revealed through empirical inquiry without a predefined categorization (e.g. Halloran et al. 2009, Iversen et al. 2010, Iversen et al. 2012, JafariNaimi et al. 2015, Le Dantec et al. 2009, Nouwen et al. 2015, Zaman \& Abeele 2010). There is also prescriptive research advising how values should be addressed in technology design. Especially value sensitive design is widely known (Friedman et al. 2013, Miller et al. 2007) while also alternative approaches have been proposed, such as value-led design (Iversen et al. 2010, Iversen et al. 2012). This paper focuses on the design context and studies how values are implicated or embedded in cross-disciplinary design and with what consequences. Naturally, some values are always driving and intermingled with design. However, so far there is a lack research considering values and their dynamics in cross-disciplinary design.

This study utilizes a grouping of universal values proposed by Schwartz (1992), which has already been used for analysing values in technology design and use (Hartikainen et al. 2019, Isomursu et al. 2011, Kinnula et al. 2018). Such research indicates this categorization fits our context. Schwartz's ten universal values include Self-Direction (independent thought and action, freedom, creativity, independency, need for control and mastery, autonomy and independence), Stimulation (excitement, novelty, challenge, variety, activation, arousal), Hedonism (pleasure, sensuous gratification, enjoyment), Achievement (personal success through demonstrating competence), Power (status, prestige, control, domination), Security (safety, harmony, stability), Conformity (not harming or upsetting others or violating social expectations, obedience, self-discipline, politeness), Tradition (respect, commitment and acceptance of cultural or religious customs or ideas), Benevolence (preserving and enhancing the welfare of others, loyalty, positive interaction), and Universalism (welfare of all people and nature) that can be organized into four higher-order groups respectively: Openness to Change; Self-Enhancement; Conservation; and Self-Transcendence (Schwartz 1992).

\section{Research design}

The paper reports results from an interpretive case study on a cross-disciplinary design project. In interpretive research, the overall goal is to understand the case in depth, to provide rich descriptions and to grasp the informants' point of view (cf. Denzin \& Lincoln 2000, Klein \& Myers 1999). The design project under scrutiny offers an exciting setting to study how designing for the human being is accomplished in multiparty and cross-disciplinary design: the project is multi party and multinational, involving users as participants among other participants, including IT companies and research 
institutions with expertise in IT, HCI or educational sciences. The designers in the project are IT, HCI and educational science specialists, each group including several senior specialists as well as more junior ones. Users have been involved, too, but not as 'designers'. The project aimed at creating an innovative learning application. The analysis of this case covers over three years' time period of project work. Data collection method of this study is documentary analysis: data for this study consists of the project documentation generated during the timespan that the project participants have collaboratively produced. The data includes official project plans, formal project deliverables (of interest particularly requirements, design and evaluation documents), different kinds of memos and informal documents (e.g. sketches, drawings) and email discussions among the project partners addressing design. As regards the data analysis conducted by the author, first a chronological outline of the project happenings was made based on the reading of all the texts selected. All relevant texts were placed into separate documents relating to one particular, influential party taking part in the design process (HCI specialists, educational science specialists, IT specialists, users). The texts were iteratively read through to understand which values were driving each party's design, asking what seemed to be considered 'good, valuable, right' for the user of the forthcoming application, paying attention to the most common aspects for each party. Particularly attention was paid to the more formal deliverables created in the project. A heterogeneous list of values and related aspects was generated, for making sense of which values theories were used as a sensitizing device (Klein \& Myers 1999): after inductive identification of values, the categorization of universal values proposed by Schwartz (1992) was found to fit the data best and was thus utilized to map the findings.

\section{Empirical insights}

\subsection{Educational science specialists' values shaping design}

The educational science specialists were a highly influential group in the project. They ideated the entire project and they were the ones who defined the requirements for the forthcoming learning application. They started to identify and communicate the requirements to other project parties soon after the project started. They sent documentation for the IT specialists and HCI specialists to comment. Then, they started more formal work related to two important deliverables, Educational Requirements and Educational Design. They were collaboratively produced and commented on by the educational science specialists. When examining the educational science specialists' design, a number of values could be identified. Prominent among them were Self-Direction, Stimulation Hedonistic, Achievement, Tradition and Security values. The application under development was a learning application and thus learning and competence development characterized all texts produced by the educationalist science specialists, indicating the prominence of Achievement value. Taking a closer look at what type of learning and competence development was addressed and how, one can identify a number of other values driving the design. Particularly, Self-Direction, Hedonistic and Stimulation values emerged as important in the sense of play, enjoyment, creativity and inspiration. The application aimed at offering users "an enjoyable and playful activity" and "playful meaning making with a multitude of possibilities.". Development of users' "creative and expressive skills" and "fostering creativity and expression" to "create endless possibilities of new and novel" were highlighted. Interestingly, very different concerns also characterized the texts. Security value can be connected with ease of use and familiarity that were heavily accentuated. The support and guidance needed by learners were emphasized, both for use and learning. Users were to be guided to the use of the application and through their learning process: "The general structure of user interface should be as simple as possible." "Combining text and visual materials is avoided as well as abstract symbols." "Hierarchical decision-making (...) is to be avoided." Collaboration among learners was deemed to contribute to ease of use and learning: "collaboration allows users to share cognitive load." Additionally, Benevolence value was emphasized. The application was to "develop social and community-related skills", "collaboration with peers", "sharing of materials and experiences", and "helping peers". The main features for collaboration were "pair game", "open workshop" and "online community": "In the online community, users also learn to share and discuss their [material] (...), and help each other." There should be "discussion, self- and peer-assessment." Finally, another 
recurrent value was Tradition, especially in the sense of cultural sensitivity connected with: "task structures", "visual elements" and used material.

\subsection{HCI specialists' values shaping design}

The goal of the HCI specialists' work was to ensure "user-centeredness" and "usability" of the application. They started the project work mainly by commenting on the work done by the educational science specialists. They entered the scene more visibly when they initiated fieldwork with users. This happened after a few months of project work. Based on their fieldwork and evaluations, they proposed Usability Requirements and Usability Design for the application. The Usability Requirements contained HCI design guidelines, and more importantly, the results from their empirical studies carried out with users in which feedback to design as well as users' ideas, designs and preferences were gathered. The Usability Design document presented the user interface screens and user interaction with the system. While producing it, the HCI specialists extensively paper prototyped with users to ensure that the design was suitable for users. After implementation of the application, the HCI specialists evaluated it through expert usability evaluations and usability testing with users. The dominating value in their work was clearly Security, interpreted as ease of use, understandability and familiarity that were in their documentation positioned as highly significant: "Use of icons needs special care - they must be understandable to the users." "Please be informed that we tested [it] already with the users. (...) It was just too confusing thing." "The guidance given by the tutor remains too limited." Users were also positioned as a bit clumsy and in need of welldesigned devices to prevent errors: "The users' manner of holding the device could often result in them unintentionally touching the screen, and hence causing errors." The HCI specialists also pointed out that users are a vulnerable group in need of protection and guidance as regards security and privacy: "Users need to be aware of the potential complex security aspects associated with the device (...). Users need to know what data on the device is special to them and what is being globally held.." On the other hand, users were also portrayed as highly capable, inspiring and creative participants in the design process. Even more authority was requested for users in the design process by the HCI specialists. Here, one can argue that Self-Direction and Stimulation values were emphasized, arguing for users' increased possibilities for independent thought and action (Schwartz 1992). The HCI specialists wondered whether the extensive help provided by a tutor was too much: "The only means to fasten the use is to press the picture of the tutor, when it comes to give the guidance. Then the tutor goes away. Should users be allowed to remove the tutor from use?" The texts painted a picture of users as very creative and inspiring co-designers: "When [users] created their own [application], first by drawing and then by building prototypes, users were very creative." Due to this, the HCI specialists tried to make other project parties to take the users more seriously into account: "I just remind of the attractive users we have "as a team-workers" in the background."

\subsection{IT specialists' values shaping design}

Similarly to HCI specialists, the IT specialists initially commented on the work done by the educational science specialists. Furthermore, they identified and experimented with the most cuttingedge technological possibilities relevant for the forthcoming application. The IT specialists created prototypes and enthusiastically communicated their ideas to other project partners. This indicates the existence of Stimulation value orientation: "I have been thinking about this multi touch (or actually multipoint) issue. (...) I tried this out and I think it works pretty well! (....) Try it out!" "About effects of icons: [a link is provided]. I just made this video of current implement-ed situation. Elements are moving all the time. When element is dragged, it transforms (slowly and nicely) its original shape and then stop all effects." Another way the IT specialists contributed to design was by commenting the educational science specialists' and HCI specialists' designs. Their comments emphasized Security value. They focused on ensuring ease of use and brought up design conventions and consistency: "It depends whether you expect users to use the device for something else than [using the application] only. If they have experience with other applications also, they are familiar with the general user interface style of the device. In that case they do know that the back arrow is on the top-right corner, and will also expect that from [the application]." The IT specialists put their source code and 
prototypes available to an open source software repository for other partners (and everyone else) to view: "I really encourage all participants to make their results public if there is no specific reason to keep those secret. We ought to be constructing open source software." "I would say that this is a very important indication of our [application] being truly an open solution and surely we should allow the interested external parties to contribute!" They wished that outsider developer-users started to contribute to the project. They claimed power for users to adopt and adapt the solution to their needs and wishes. This can be connected with the Self-Actualization value.

\subsection{Users' values shaping design}

When users initially encountered the application, their reaction was positive overall. They seemed to enjoy playing the game: "Users got excited about the game." "The use was immersive." "Icons ... were appealing ... and engaging." "She enjoyed the game and would have wanted to play even longer than the 30 minutes." Enjoying the activity itself indicates that Hedonistic value can be associated with the application use. For some, alternatively, there also seemed to be a lack of Hedonistic value as they did not enjoy the activity supported by the game: "She was hesitant in her abilities in this activity. She experienced the game to be difficult in times. ... She said aloud she is not good in this activity." "First impression was not exciting enough. Recognition of the material required hard work." Then again, Self-Actualization value could be connected with the application: "Playing the game seemed to be suitably challenging for the users." "The material activated her, and the outcome was good." However, there were also problems identifiable. the value of Self-Actualization not being realized: "There were too few functions taking into account the users wanted to play the game more." Learning was guided by the tutor feature that seemed to be appreciated "The feedback provided by the tutor motivated the users." Then again, for some the Security value was under-emphasized: "The activity was difficult and there was nothing easy about this game." "She wasn't excited about the game and probably it was because she felt that she couldn't play it." For some, furthermore, the Security value was overemphasized and the tutor feature seemed to be overactive: "Too extensive feedback (the tutor pops up on the screen often) is disturbing for some users." "Some of the users did not want to listen to the guidance but started pressing buttons before the tutor stopped." It the designers decided that: "One needs to be able to stop the tutor speech if needed and also to leave it out entirely."

\subsection{Value conflict and convergence}

As is evident, all the designer groups emphasized Security and Self-Actualization values in their designs for users: they wanted users to develop, learn and build competence as well as to do it in a safe and easy manner. Additionally, the educational science specialists and IT specialists emphasized Stimulation value for users: an opportunity to experience novelty, curiosity and inspiration. However, the picture was not this nice and neat. There was variety within these shared value orientations, there were value conflicts in the designs created by different parties and one can even claim that there were value conflicts in the designs created by one and only party. Albeit all parties emphasized Security value, the IT specialists interpreted it as ease of use achieved by following design conventions, the $\mathrm{HCI}$ specialists as ease of use that can be achieved by empirically examining users and matching the solution with them, and the educational science specialists as ease of learning. All this was not necessarily a problem, as occasionally all these orientations could be combined in one and only design, but there were also cases in which this could not be done. Disagreements emerged between the educational science specialists and the HCI specialists during design. The HCI specialists used their user data to convince the others of their design decisions. Especially they emphasized Security value in the sense of ease of use in their arguments. The educational science specialists accepted certain changes; however, they did not accept them all. The educational science specialists referred to the project goals related to learning and development, to user interface consistency as well as to cultural sensitivity when declining to make changes. Here, one can argue that Achievement value was prioritized over Security by the educational science specialists. Pedagogical design overruled usability considerations. Moreover, cultural sensitivity was prioritized over certain familiarity or understandability concerns, i.e. Tradition value was prioritized over Security in this case. Value 
theories maintain that indeed values form hierarchies showing the relative importance of different values (Schwartz 1992, Schwartz 1994). In this project, educational science specialists' Achievement and Tradition values overruled Security value, while all parties emphasized Security value as significant for users. Interestingly, value theories (Schwartz 1992, Schwartz 1994) also posit that certain kinds of values are in conflict with each other: change oriented (e.g. Stimulation, SelfActualization, Hedonistic) with stability oriented (e.g. Security, Tradition) as well as individual oriented (e.g. Hedonistic, Self-Actualization) with collective oriented (e.g. Tradition). When applied to our data, one can say that there was a number of values in the designs that were in conflict with some other values embedded in the same design. Especially this was the case in the educational science specialists' design, in which a pursuit of a variety of values (Self-Actualization, Hedonistic, Stimulation, Tradition, Security) was identified. The theory posits that the Self-Actualization, Hedonistic and Stimulation values conflict with the Tradition and Security values (Schwartz 1992, Schwartz 1994). As implied by the educational science specialists' design, users are to be Achievement, Hedonism, Stimulation and Self-Actualization oriented as well as Tradition and Security preserving. This might cause psychological or social conflicts (cf. Schwartz 1992, Schwartz 1994). IT and HCI specialists also advocated conflicting values in design (Self-Actualization versus Security). However, this unlikely causes problems for users as the Security value clearly dominated and the Self-Actualization value was more related to users' participation in the design process.

\section{Concluding discussion}

Research is limited in acknowledging the influence of values embedded in and shaping creative design, including cross-disciplinary design. This paper started to fill in this research gap.

\subsection{Variety of values, their conflicts, convergence, evolution, negotiation}

Table 1. Values underlying design and value conflicts and convergence in cross-disciplinary design

\begin{tabular}{|c|c|c|}
\hline Stakeholder & Values & Value convergence and conflicts \\
\hline $\begin{array}{l}\text { Educational } \\
\text { science } \\
\text { specialists } \\
\text { designing for } \\
\text { learner }\end{array}$ & $\begin{array}{l}\text { Achievement; Self- } \\
\text { Direction; } \\
\text { Stimulation; } \\
\text { Hedonistic; } \\
\text { Tradition; Security }\end{array}$ & $\begin{array}{l}\text { - Convergence: with HCI, IT specialists and users Self-Actualization } \\
\text { and Security values, with IT specialists Stimulation value } \\
\text { - Conflicts: with HCI specialists Tradition vs. Security values, Self- } \\
\text { Actualization vs. Security values, with users Self-Actualization, } \\
\text { Hedonistic vs. Security values }\end{array}$ \\
\hline $\begin{array}{l}\text { HCI } \\
\text { specialists } \\
\text { designing for } \\
\text { user }\end{array}$ & $\begin{array}{l}\text { Security; Self- } \\
\text { Direction; } \\
\text { Stimulation }\end{array}$ & $\begin{array}{l}\text { - Convergence: with educational science, IT specialists and users Self- } \\
\text { Actualization and Security values } \\
\text { - Conflicts: with educational science specialists Tradition vs. Security } \\
\text { values and Self-Actualization vs. Security values, with users Self- } \\
\text { Actualization, Hedonistic vs. Security values }\end{array}$ \\
\hline $\begin{array}{l}\text { IT specialists } \\
\text { designing for } \\
\text { user }\end{array}$ & $\begin{array}{c}\text { Security; } \\
\text { Stimulation; Self- } \\
\text { Direction }\end{array}$ & $\begin{array}{l}\text { - Convergence: with educational science, HCI specialists and users } \\
\text { Self-Actualization and Security values, with educational science } \\
\text { specialists Stimulation value } \\
\text { - Conflicts: with users Self-Actualization, Hedonistic versus Security } \\
\text { values }\end{array}$ \\
\hline Users & $\begin{array}{l}\text { Hedonistic; Self- } \\
\text { Actuali-zation; } \\
\text { Security }\end{array}$ & $\begin{array}{l}\text { - Convergence: with educational science, HCI specialists and users } \\
\text { Self-Actualization and Security values, with educational science } \\
\text { specialists Stimulation value } \\
\text { - Conflicts: with educational science, HCI, IT specialists and other } \\
\text { users Self-Actualization, Hedonistic vs. Security values }\end{array}$ \\
\hline
\end{tabular}

The empirical results show the complex nature of design, including cross-disciplinary design, and how values are intermingled in such a design - regarding both the process and the outcome. This study shows that both value conflicts and value congruence characterize cross-disciplinary design. The IT and HCI specialists had a shared value orientation. In addition to Security value, they had a concern for user Self-Actualization in the sense of inviting users to contribute more strongly. The IT specialists were wishing technology savvy open source developer-users to join the project, 
while the HCI specialists prioritized users without such specialized knowledge. In a sense, both parties can be argued of sharing some participatory design (PD) values relating to user empowerment, while both can also be criticized as being quite far away of empowerment in the sense of PD tradition. This case shows that the educational science and HCI specialists were not far from each other in their design work and value orientation either. Both placed a lot of emphasis on Security value (ease of using, learning). Both assumed that users are in need of guidance and protection. Such concerns are valid for HCI specialists, even if one may also criticize that the HCI specialists addressed quite a limited and traditional set of values. They could have considered User Experience more broadly and not focused so heavily only on ensuring ease of use, leaving all functionality considerations for the educational science specialists. Then again, these two designer groups also had their disagreements and value conflicts emerged. These revolved around the need to support learning versus ease of use. The educational science specialists' main concern was to enable learning and competence development and HCI specialists' ease of use concerns were not prioritized over those. This is not very surprising in the case of a learning application. Interestingly, this study revealed that the IT specialists were not the 'evil' against whom to fight on behalf of the users in this cross-disciplinary case, but instead the 'soft side' ended up in conflicts while trying to accomplish the same goal: to produce high quality solutions for human use. This emerged surprisingly; additional effort would have been needed for orchestrating the design process. Future research is needed for explicating how to organize cross-disciplinary design when aiming at high-quality solutions for human use, where there are numerous experts and disciplines involved. This case also made visible how values are evolving in design (e.g. Halloran et al. 2009): while Security value seemed to be highly significant for all the designer groups early on, users managed to point out that it was over-emphasized in the application design and hence it became reduced. Thus, users managed to initiate negotiation around design and change in value orientation.

\subsection{Implications for design}

This study underscores the importance of dialogue on values in design, particularly in crossdisciplinary. In this project no explicit discussion of values was carried out; they were revealed post hoc. However, likely these values should have been explicitly discussed during the design process. Value sensitive design could have been valuable, guiding to identifying benefits and harms that can be associated with different stakeholders and to explicit analysing those in relation to universal human values. Potential value conflicts or tensions could have been addressed early during the design process. (Friedman et al. 2013, Miller et al. 2007) Value-led design, furthermore, could have guided even more explicitly to a dialogic process among the stakeholders, with whom the context specific, local values could have been discussed and the values embedded in design and action negotiated collaboratively (Iversen et al. 2010, Iversen et al. 2012). A more explicit handling of values might have helped to alleviate the tensions that emerged during the design process. In addition, the design solution might have been totally different if this value work had been used to guide the design process.

\subsection{Limitations and paths for future work}

The results are based on one case only; data should be gathered from other cross-disciplinary cases to see whether the results hold with other settings and disciplines. An interesting topic would be to inquire how users interpret and approach the application in use that involves production of new meanings and values (Halloran et al. 2009, Le Dantec et al. 2009, JafariNaimi et al. 2015) not totally determinable by the designers. Examining context dependent values emerging (Halloran et al. 2009, Le Dantec et al. 2009, JafariNaimi et al. 2015) would also be interesting to study as well as cultural aspects intermingled with this type cross-disciplinary design process with different value orientations.

\section{References}

Bergman, M., Lyytinen, K., \& Mark, G. (2007). Boundary objects in design: An ecological view of design artifacts. Journal of the Association for Information Systems, 8(11), 546. 
Cummings, J., \& Kiesler, S. (2003). Coordination and success in multidisciplinary scientific collaborations. In Proc. International Conference on Information Systems 2003, 25.

Denison, D.R. and Spreitzer, G.M. (1991). Organizational culture and organizational development: A competing values approach. In R. Woodman \& W. Pasmore (Eds.). Research in Organizational Change and Development, Volume 5 (pp. 1-21), Greenwich: JAI Press Inc.

Denzin, N. \& Lincoln, Y. (2000). Introduction: The Discipline and Practice of Qualitative Research. In N. Denzin \& Y. Lincoln (Eds.). Handbook of Qualitative Research (pp. 1-29). Thousand Oaks: Sage.

Friedman, B., Kahn Jr, P. H., Borning, A., \& Huldtgren, A. (2013). Value sensitive design and information systems. In N. Doorn, D: Schuurbiers, I. van de Poel, M. Gorman (Eds.). Early engagement and new technologies: Opening up the laboratory (pp. 55-95). Dordrecht: Springer.

Gasson, S. (2012). The Sociomateriality Of Boundary-Spanning Enterprise IS Design. In Proc. International Conference on Information Systems 2012.

Halloran, J., Hornecker, E., Stringer, M., Harris, E. and Fitzpatrick, G. (2009). The value of values: Resourcing co-design of ubiquitous computing. CoDesign, 5(4), 245-273.

Hartikainen, H., Iivari, N., \& Kinnula, M. (2019). Children's design recommendations for online safety education. International Journal of Child-Computer Interaction, 22, 100-146.

Hekkala, R., \& Urquhart, C. (2013). Everyday power struggles: living in an IOIS project. European Journal of Information Systems, 22(1), 76-94.

Iivari, N., Kinnula, M., \& Kuure, L. (2015). With best intentions. Information Technology \& People, 28(2), 246280.

Isomursu, M., Ervasti, M., Kinnula, M., \& Isomursu, P. (2011). Understanding human values in adopting new technology - a case study and methodological discussion. International journal of human-computer studies, 69(4), 183-200.

Iversen, O., Halskov, K., \& Leong, T. (2010). Rekindling values in participatory design. In Proc. Participatory Design Conference 2010.

Iversen, O, Halskov, K., \& Leong, T. (2012). Values-led participatory design. CoDesign, 8(2-3), 87-103.

JafariNaimi, N., Nathan, L. and Hargraves, I. Values as Hypotheses: Design, Inquiry, and the Service of Values. Design Issues, 31(4), 91-104.

Kinnula, M., Iivari, N., Isomursu, M., \& Kinnula, H. (2018). Socializers, achievers or both? Value-based roles of children in technology design projects. International Journal of Child-Computer Interaction, 17, 39-49.

Klein, H. \& Myers, M. (1999): A set of principles for conducting and evaluating interpretive field studies in information systems. MIS quarterly, 23(1), 67-93.

Le Dantec, C. A., Poole, E. S., \& Wyche, S. P. (2009). Values as lived experience: evolving value sensitive design in support of value discovery. In Proc.SIGCHI conference on human factors in computing systems (pp. 1141-1150).

Lee, C. (2007). Boundary Negotiating Artifacts: Unbinding the Routine of Boundary Objects and Embracing Chaos in Collaborative Work. Computer Supported Cooperative Work, 16(3), 307-339.

Levina, N. (2006). Collaborating on Multiparty Information Systems Development Projects: A col-lective Reflection-in-Action View. Information Systems Research, 16(2), 109-130.

Miller, J. K., Friedman, B., Jancke, G. \& Gill, B. (2007). Value tensions in design: the value sensitive design, development, and appropriation of a corporation's groupware system. In Proc. International ACM conference on Supporting group work (pp. 281-290).

Newell, S., \& Galliers, R. D. (2000). More than a footnote: The perils of multidisciplinary research collaboration. In Proc. American Conference on Information Systems 2000.

Nouwen, M., Van Mechelen, M., \& Zaman, B. (2015). A value sensitive design approach to parental software for young children. In Proc. International Conference on Interaction Design and Children (pp. 363-366).

Rosenkranz, C., Vranesic, H., \& Holten, R. (2014). Boundary interactions and motors of change in requirements elicitation: a dynamic perspective on knowledge sharing. Journal of the Association for Information Systems, 15(6), 306.

Schutz, D. M., Kim, Y. Y., Yoo, Y., \& Pavlou, P. A. (2009). An Empirical Investigation on the Role of IT Materiality in Multidisciplinary Innovation. In Proc. International Conference on Information Systems 2009.

Schwartz, S. H. (1992). Universals in the content and structure of values: Theoretical advances and empirical tests in 20 countries. Advances in experimental social psychology, 25(1), 1-65.

Schwartz, S. H. (1994). Are there universal aspects in the structure and contents of human values? Journal of social issues, 50(4), 19-45. 
Zaman, B., \& Abeele, V. V. (2010). Laddering with young children in User Experience evaluations: theoretical groundings and a practical case. In Proc. International Conference on Interaction Design and Children (pp. 156-165). 